\title{
Erratum to: Caring for Pregnant Women with Opioid Use Disorder in the USA: Expanding and Improving Treatment
}

\author{
Kelley A. Saia ${ }^{1}$ - Davida Schiff ${ }^{2} \cdot$ Elisha M. Wachman ${ }^{2} \cdot$ Pooja Mehta $^{1}$. \\ Annmarie Vilkins ${ }^{1}$ - Michelle Sia ${ }^{1}$ - Jordana Price ${ }^{3}$. Tirah Samura ${ }^{1}$. \\ Justin DeAngelis ${ }^{1}$ - Clark V. Jackson ${ }^{4}$ - Sawyer F. Emmer ${ }^{5}$ - Daniel Shaw ${ }^{6}$. \\ Sarah Bagley ${ }^{7}$
}

Published online: 13 September 2016

(C) Springer Science+Business Media New York 2016

Erratum to: Curr Obstet Gynecol Rep (2016) 5(3): 257 - 263

DOI 10.1007/s13669-016-0168-9

The original paper of this article unfortunately contains error. Dr. Pooja Mehta's Conflict of Interest information was incorrectly listed in the publication. Her correct COI information is as follows:
Dr. Pooja Mehta declares grant funding from American College of Obstetricians \& Gynecologists Warren H. Pearse Research Award for Women's Health Policy, and from the HRSA Maternal Child Health Bureau R20 Secondary Data Analysis, both unrelated to the submission.

The online version of the original article can be found at http://dx.doi.org/ 10.1007/s13669-016-0168-9.

Kelley A. Saia

kesaia@bu.edu

1 Department of Obstetrics and Gynecology, Boston Medical Center, 85 East Concord Street, 6th Floor, Boston, MA 02118, USA

2 Department of Pediatrics, Boston Medical Center, Boston, USA

3 Department of Family Medicine, Boston Medical Center, Boston, USA

4 Boston University School of Public Health, Boston, USA

5 Boston of University School of Medicine, Boston, USA

6 Department of Psychiatry, Boston Medical Center, Boston, USA

7 Department of Internal Medicine, Boston Medical Center, Boston, USA 